\title{
Article
}

\section{Outer-Sphere Redox Couples as Shuttles in Dye-Sensitized Solar Cells. Performance Enhancement Based on Photoelectrode Modification via Atomic Layer Deposition}

Thomas W. Hamann, Omar K. Farha, and Joseph T. Hupp

J. Phys. Chem. C, 2008, 112 (49), 19756-19764 • Publication Date (Web): 13 November 2008

Downloaded from http://pubs.acs.org on January 7, 2009

\section{More About This Article}

Additional resources and features associated with this article are available within the HTML version:

- $\quad$ Supporting Information

- $\quad$ Access to high resolution figures

- $\quad$ Links to articles and content related to this article

- Copyright permission to reproduce figures and/or text from this article

View the Full Text HTML 


\title{
Outer-Sphere Redox Couples as Shuttles in Dye-Sensitized Solar Cells. Performance Enhancement Based on Photoelectrode Modification via Atomic Layer Deposition
}

\author{
Thomas W. Hamann, ${ }^{\dagger}$ Omar K. Farha, and Joseph T. Hupp* \\ Department of Chemistry and Argonne-Northwestern Solar Energy Research Center (ANSER), \\ Northwestern University, 2145 Sheridan Road, Evanston, Illinois 60208
}

Received: August 18, 2008; Revised Manuscript Received: October 10, 2008

\begin{abstract}
Atomic layer deposition (ALD) has been used to create conformal $\mathrm{TiO}_{2}$ blocking layers on fluorine-doped tin-oxide substrates in dye-sensitized solar cells (DSSCs), effectively eliminating shunting. ALD has also been used to deposit, in controlled fashion, ultrathin coatings of alumina on nanoparticle-based $\mathrm{TiO}_{2} \mathrm{DSSC}$ photoanodes. These modified electrodes enable ferrocenium/ferrocene, an outer-sphere redox couple, to be used as a shuttle. The photovoltaic performance and interfacial charge-transfer dynamics were investigated in DSSCs employing this shuttle. It was found that a single ALD cycle is able to passivate surface states, resulting in a dramatic improvement in photovoltaic performance. Subsequent alumina deposition resulted in exponentially increasing electron lifetimes as a function of alumina layer thickness, indicating that the layers behave as barriers to electron tunneling. The characterization of DSSC photovoltaic performance and interfacial charge-transfer dynamics was extended to cells employing derivatives of ferrocenium and ferrocene featuring more positive redox potentials; these cells yielded larger open-circuit photovoltages.
\end{abstract}

\section{Introduction}

The best dye-sensitized solar cells (DSSCs) are based on nanocrystalline $\mathrm{TiO}_{2}$ and exhibit solar energy conversion efficiencies exceeding $11 \% .^{1-4}$ To date, all high-efficiency DSSCs have utilized the $\mathrm{I}_{3}^{-} / \mathrm{I}^{-}$couple as a redox shuttle. The good performance of these cells is attributable, in part, to the slow, and likely mechanistically complex, nature of back electron transfer (ET) reactions from $\mathrm{TiO}_{2}$ and fluorine-doped tin oxide (FTO) to triiodide. (Slow back ET allows for efficient collection of photoinjected electrons.) Nevertheless, there are substantial drawbacks to the use of the $\mathrm{I}_{3}{ }^{-} / \mathrm{I}^{-}$couple as a redox shuttle. ${ }^{5-7}$ Among them are the following: (i) appreciable limitations on the achievable open-circuit voltage due to the relatively low redox potential of the shuttle, (ii) significant limitations on the achievable photocurrent due to the inability of iodide to regenerate far-red-absorbing dyes (i.e., dyes with comparatively low redox potentials) at acceptable rates (iodide typically is effective as a dye regenerator only when the driving force for regeneration exceeds ca. $0.5 \mathrm{eV}),{ }^{8-10}$ (iii) limitations on the achievable photocurrent, due to competitive absorption of visible light by triiodide, (iv) strong association of $\mathrm{I}_{3}{ }^{-}$with highly polarizable organic chromophores (e.g., porphyrins), resulting in enhanced dark currents as well as undesirable, alternative dye reaction pathways, ${ }^{11,12}$ and (v) a propensity to corrode non-noble metal components.

Clearly it would be desirable to identify alternative, noncorrosive, and weakly absorbing redox reagents capable of functioning as dye-regenerators/photocell-shuttles under low driving-force conditions. Unfortunately, fast-exchanging, oneelectron, outer-sphere redox couples such as ferrocenium/ ferrocene $\left(\mathrm{Fc}^{+} / \mathrm{Fc}\right)$ have thus far proven ineffective as DSSC shuttles. ${ }^{13,14}$ Although ferrocene rapidly reduces the oxidized dye created by injection of an excited electron into the $\mathrm{TiO}_{2}$,

\footnotetext{
* Corresponding author e-mail: j-hupp@ northwestern.edu.

Current address: Department of Chemistry, Michigan State University, East Lansing, MI 48824-1322.
}

ferrocenium is quickly reduced by electrons in $\mathrm{TiO}_{2}$ or an underlying exposed current collector such as FTO (fluorinedoped tin oxide). ${ }^{14,15}$ Gregg et al. showed that the latter reaction (back ET from the exposed current collector) could be inhibited via self-limiting electropolymerization of phenol + allyl phenol. ${ }^{13,14}$ Additionally, they showed that $\mathrm{CH}_{3} \mathrm{SiCl}_{3}$ vapor, which reacts with surface hydroxyl groups, can readily form thin, insulating films of poly(methylsiloxane) on both nanocrystalline $\mathrm{TiO}_{2}$ and FTO surfaces. Interestingly, the silane treatment was implemented with photolectrodes that had already been loaded with chromophores. The siloxane coatings were of sufficient quality to enable $\mathrm{Fc}^{+} / \mathrm{Fc}$ to function to some extent as a redox shuttle. While noting the promise of this approach, the authors pointed to limitations, including poor reproducibility, nonuniform coating, limited control of coating thickness, and propensity for capillary condensation of the chlorosilane within $\mathrm{TiO}_{2}$ pores (resulting in pore blockage).

In principle, the inhibitory effects of surface modifiers on ET kinetics at photoelectrode/solution interfaces can have any of three origins: (a) passivation of unusually reactive surface states, ${ }^{16}$ (b) shifting of the conduction band edge energy, ${ }^{17}$ and/ or (c) diminution of initial-state/final-state electronic coupling based on physical separation of the electron donor (photoelectrode) and electron acceptor (oxidized redox shuttle). The dependence of the rate of back electron transfer from $\mathrm{TiO}_{2}$ to covalently attached oxidized dyes on separation distance has been examined in several studies. ${ }^{18-21}$ In addition, back-ET reactions from $\mathrm{SnO}_{2}$ to electrostatically bound dyes featuring alkyl substituents of various lengths have been reported to exhibit distance-dependent rate constants. ${ }^{22}$ Further, it was recently determined that tert-butyl groups can act as spacers on an outer-sphere redox couple, thereby significantly decreasing electronic coupling for interfacial electron-transfer reaction at a $\mathrm{ZnO}$ single crystal electrode. ${ }^{23}$ Together, these studies imply that systematic control of separation distance may be a very useful strategy for modulating rate constants for transfer of electrons from a semiconductor electrode to a redox shuttle. 
An alternative approach to controlling electrode/molecule separation distance, and therefore electronic coupling and backET reactivity, would be to employ insulating metal oxides as barrier layers. Indeed, several wide-band gap materials, including $\mathrm{ZrO}_{2},{ }^{24-27} \mathrm{Al}_{2} \mathrm{O}_{3},{ }^{16,24,28-30} \mathrm{Nb}_{2} \mathrm{O}_{5},{ }^{26,27}$ and $\mathrm{SiO}_{2},{ }^{24}$ have been used as barrier-layer coatings in DSSCs. While no significant improvement in conversion efficiency has been described-in most cases, the barrier layers actually worsen cell performance-it has been shown that barrier layers are able to reduce the rates of transfer of injected electrons back to oxidized sensitizer molecules and/or the redox shuttle $\left(\mathrm{I}_{3}^{-} / \mathrm{I}^{-}\right.$; to our knowledge, no studies with other shuttles have been reported), as well as the rates for forward electron injection. ${ }^{16,24,31}$ The investigated metal oxide barrier layers were prepared by "dip-coat" methods, producing nonconformal and nonuniform layers with difficultto-determine thicknesses. ${ }^{31}$ It is important to note that thin layers of $\mathrm{Al}_{2} \mathrm{O}_{3}$ or other metal oxides prepared by dip-coating are likely not pinhole-free. ${ }^{31}$ Pinholes are not expected to have a significant effect on the retardation of dye injection or recombination kinetics as long as most of the dye is bound to the barrier layer, ${ }^{32}$ thus permanently separating the dye and the semiconductor. For a barrier layer to be effective in slowing the interception of injected electrons by an outer-sphere redox shuttle, on the other hand, the layer must be essentially pinhole-free-as the solutionphase shuttle can diffuse to pinholes, with reactivity there then dominating the kinetics.

We reasoned, however, that the metal oxide barrier approach could be adapted for our purposes (i.e., understanding and producing DSSCs that can function well with simple outersphere redox couples as regenerators and shuttles) if the oxide fabrication method was highly reproducible and if it was capable of producing robust, conformal, pinhole-free films with nearangstrom control over thickness, even on highly irregular, porous photoelectrode surfaces. Atomic layer deposition (ALD) meets these requirements ${ }^{33}$ and, in fact, has been used with good success in several recent photoelectrochemical and closely related studies. ${ }^{28,34-38}$ In the work described below, ALDfabricated $\mathrm{TiO}_{2}$ was examined as a blocking layer on FTO for elimination of shunting. ALD was further used to deposit conformal, ultrathin pinhole-free layers of $\mathrm{Al}_{2} \mathrm{O}_{3}$ on $\mathrm{TiO}_{2}$ nanoparticle photoanodes, with the aim of slowing interception of injected electrons by an oxidized shuttle $\left(\mathrm{Fc}^{+}\right)$. The mechanisms by which the alumina layers affect the interception rate are discussed. The exponential modulation of the interception dynamics with thickness of $\mathrm{Al}_{2} \mathrm{O}_{3}$ on $\mathrm{TiO}_{2}$ allowed for estimation of the tunneling parameter, $\beta$. The modified electrodes enabled the use of a homologous series of nonadsorbing oneelectron outer-sphere redox shuttles. Results from the series demonstrate that the photovoltage can be controlled through systematic derivatization of shuttle compounds.

\section{Experimental Section}

Atomic layer deposition was performed with a Savannah 100 instrument (Cambridge Nanotech Inc.). Photoelectrodes were prepared on $12 \Omega \mathrm{cm}^{-2}$ FTO-coated glass (Hartford glass). Blocking layers of $\mathrm{TiO}_{2}$ were deposited using 400 ALD cycles of titanium isopropoxide (Aldrich), TIP, and water as precursors. $\mathrm{TiO}_{2}$ was grown at $200{ }^{\circ} \mathrm{C}$ using reactant exposure times of 1 and $0.02 \mathrm{~s}$ for TIP and $\mathrm{H}_{2} \mathrm{O}$, respectively, and nitrogen purge times of $10 \mathrm{~s}$ between exposures. A transparent $\mathrm{TiO}_{2}$ nanoparticle layer was prepared by doctor blading a paste of $\mathrm{TiO}_{2}$ nanoparticles (DSL 18NR-T, Dyesol) on the FTO. A scattering layer of $\mathrm{TiO}_{2}$ nanoparticles (WER4-O, Dyesol) was subsequently deposited on top of the transparent layer. The resulting electrodes were annealed at $500{ }^{\circ} \mathrm{C}$ in air for $30 \mathrm{~min}$. The thicknesses of the transparent and scattering layers of the photoelectrodes were approximately 8 and $3 \mu \mathrm{m}$, respectively, measured using a Tencor P10 profilometer. Alumina was deposited immediately following removal from the oven by ALD using trimethylaluminum (TMA (Aldrich)) and water as precursors. $\mathrm{Al}_{2} \mathrm{O}_{3}$ was grown at $200{ }^{\circ} \mathrm{C}$ using reactant exposure times of $10 \mathrm{~s}$ for both precursors and nitrogen purge times of $20 \mathrm{~s}$ between exposures.

The $\mathrm{TiO}_{2}$ electrodes were immediately immersed in a $0.5 \mathrm{mM}$ solution of $\left[\mathrm{Ru}(4,4 \text { '-dicarboxy-2,2'-bipyridine })_{2}(\mathrm{NCS})_{2}\right]$ ("N3", Dyesol, B4 dye) in ethanol. After $\sim 20 \mathrm{~h}$, they were rinsed with ethanol and dried with $\mathrm{N}_{2}$. A Surlyn frame was sandwiched between the open-pore side of the membrane and a platinized FTO electrode. Light pressure was applied at $130{ }^{\circ} \mathrm{C}$ to seal the cell.

Photoelectrodes consisting of an $\sim 8 \mu \mathrm{m}$ thick transparent layer of $\mathrm{TiO}_{2}$ nanoparticles were prepared as described above, with the exception that no scattering layer was added. Electrodes were coated with $0,1,2,3,4$, and 5 ALD cycles of $\mathrm{Al}_{2} \mathrm{O}_{3}$ immediately after sintering. The series of electrodes were cooled to room temperature and immersed in an ethanolic catechol solution $(\sim 5 \mathrm{mM})$ for $\sim 30 \mathrm{~min}$. Electrodes were removed from the catechol solution, rinsed with ethanol, and dried with a nitrogen stream, and UV-vis spectra were taken immediately. A control electrode was prepared identically, except they were soaked in ethanol without catechol.

Ferrocene (Alfa Aesar) and ferrocenium tetrafluoroborate (Aldrich) were used as received. Chloroferrocene, $\mathrm{Fe}\left(\mathrm{C}_{5} \mathrm{H}_{5}\right)\left(\mathrm{C}_{5} \mathrm{H}_{4} \mathrm{Cl}\right)$, and 1,1'-dichloroferrocene, $\mathrm{Fe}\left(\mathrm{C}_{5} \mathrm{H}_{4} \mathrm{Cl}\right)_{2}$, were prepared by modified literature procedures as follows. Chloroferrocene $(\mathrm{Fc}-\mathrm{Cl})$ was synthesized by modifying the procedure described by Nefedov et al. ${ }^{39}$ Ferrocenylboronic acid (1.00 g, $4.35 \mathrm{mmol}), \mathrm{CuCl}_{2} \cdot 2 \mathrm{H}_{2} \mathrm{O}$ (1.2 g, $7.04 \mathrm{mmol}$ ), and 100 $\mathrm{mL}$ of distilled water were placed in a $250 \mathrm{~mL}$ one-neck roundbottom flask and refluxed for $3 \mathrm{~h}$ (bath temperature was 250 $\left.{ }^{\circ} \mathrm{C}\right)$. The solution was cooled to room temperature, and the crude product was extracted with $\mathrm{CH}_{2} \mathrm{Cl}_{2}(3 \times 100 \mathrm{~mL})$. The organic fractions were combined and concentrated by a rotary evaporator. A silica plug was applied with hexanes as eluent. The hexane was evaporated, and the red-orange solid was recrystallized from hexanes. The pure product (orange solid) was filtered and dried under vacuum $(0.83 \mathrm{~g}, 87 \%) .{ }^{1} \mathrm{H}$ NMR (300 MHz, $\left.\mathrm{CDCl}_{3}\right)$ : $\delta=4.04(2 \mathrm{H}), 4.22(5 \mathrm{H}), 4.38(2 \mathrm{H}) .{ }^{13} \mathrm{C} \mathrm{NMR}(75.5 \mathrm{MHz}$, $\left.\mathrm{CDCl}_{3}\right): \delta=66.3,68.1,70.5$, 92.6. Calculated for $\mathrm{C}_{10} \mathrm{H}_{9} \mathrm{ClFe}$ : C, 54.4; H, 4.1; Found: C, 54.6; H, 4.2.

Dichloroferrocene $\left(\mathrm{Fc}-(\mathrm{Cl})_{2}\right)$ was synthesized by modifying and combining procedures described by Phillips et al. and Kovar et al. ${ }^{40,41}$ Sublimed ferrocene ( $5.0 \mathrm{~g}, 26.88 \mathrm{mmol}$ ) was dissolved in $200 \mathrm{~mL}$ of distilled hexane. $N, N, N^{\prime}, N^{\prime}$-tetramethylethylenediamine (8.96 mL, $59.76 \mathrm{mmol}$, distilled from sodium) and $n$-BuLi (23.90 mL of $2.5 \mathrm{M}$ in hexanes, $59.76 \mathrm{mmol}$ ) were mixed and allowed to stand for $15 \mathrm{~min}$ to form a complex. The former solution was added quickly to the ferrocene solution under a nitrogen atmosphere. This mixture was stirred at room temperature for $6 \mathrm{~h}$. The solution was then cooled to $-78{ }^{\circ} \mathrm{C}$ and tosyl chloride (11.39 g, $59.76 \mathrm{mmol})$ was added. The reaction mixture was allowed to warm to room temperature and stirred for $15 \mathrm{~h}$. A silica plug was then applied with hexanes as eluent, and the yellow band was collected. The solvent was removed in vacuo, yielding a mixture of ferrocene, chloroferrocene, and 1,1'-dichloroferrocene in an approximate ratio of 15:15:70. The mixture was dissolved in $50 \mathrm{~mL}$ of methanol, $3 \mathrm{~g}$ of $\mathrm{AgNO}_{3}$ were added, and the solution was stirred at room temperature for $1 \mathrm{~h}$. Water $(50 \mathrm{~mL})$ was then added, and a 
yellow-orange product was extracted with cyclohexane $(3 \times$ $100 \mathrm{~mL}$ ). The organic fractions were combined, and the solvent was removed in vacuo. The orange solid was then recrystallized twice from hexanes to give pure product as an orange solid (3.1 g, 55\%). ${ }^{1} \mathrm{H}$ NMR (300 $\left.\mathrm{MHz}, \mathrm{CDCl}_{3}\right): \delta=4.15(4 \mathrm{H})$, $4.44(4 \mathrm{H}) .{ }^{13} \mathrm{C} \mathrm{NMR}\left(75.5 \mathrm{MHz}, \mathrm{CDCl}_{3}\right): \delta=68.7,70.2,93.4$. Calculated for $\mathrm{C}_{10} \mathrm{H}_{8} \mathrm{Cl}_{2} \mathrm{Fe}$ : C, 47.1; H, 3.2; Cl, 27.8; Found: C, 46.3; H, 3.2; Cl, 27.6.

Chloroferrocenium and dichloroferrocenium were prepared following a literature procedure for ferrocenium. ${ }^{42}$ Briefly, a solution of 2 equiv of $\mathrm{Fc}-\mathrm{Cl}$ or $\mathrm{Fc}-(\mathrm{Cl})_{2}$ in diethyl ether was added to a solution of $\mathrm{HBF}_{4} \cdot \mathrm{OEt}_{2}(\sim 4$ equiv) and $p$-benzoquinone (1 equiv) in diethyl ether while stirring. A blue solid precipitated and was removed by filtration, washed with diethyl ether, and dried in vacuo. Calculated for $\mathrm{C}_{10} \mathrm{H}_{9} \mathrm{ClFeBF}_{4}$ : C, 39.1; H, 2.9; Cl, 11.5; Found: C, 39.0; H, 2.9; Cl, 11.7. Calculated for $\mathrm{C}_{10} \mathrm{H}_{8} \mathrm{Cl}_{2} \mathrm{FeBF}_{4} \cdot 3 \mathrm{H}_{2} \mathrm{O}: \mathrm{C}, 29.9 ; \mathrm{H}, 3.4 ; \mathrm{Cl}, 17.7 ; \mathrm{F}, 18.9$; Found: C, 30.2; H, 2.5; Cl, 16.7; F, 18.7.

Acetonitrile solutions containing $0.1 \mathrm{M}$ ferrocene species $(\mathrm{Fc}$, $\mathrm{Fc}-\mathrm{Cl}$, or $\left.\mathrm{Fc}(\mathrm{Cl})_{2}\right), 0.01 \mathrm{M}$ ferrocenium species $\left([\mathrm{Fc}] \mathrm{BF}_{4}\right.$, $\left([\mathrm{Fc}-\mathrm{Cl}] \mathrm{BF}_{4}\right.$, or $\left(\left[\mathrm{Fc}-(\mathrm{Cl})_{2}\right] \mathrm{BF}_{4}\right)$, and $0.20 \mathrm{M}$ tetrabutylammoniumtetrafluoroborate, $\mathrm{TBABF}_{4}$, were deoxygenated by bubbling with $\mathrm{N}_{2}$, introduced into $\mathrm{TiO}_{2}$ cells, and examined immediately. $\mathrm{LiClO}_{4}(30 \mathrm{mM})$ was added to some electrolyte solutions as indicated in the text. The iodide electrolyte consisted of 0.6 M TBAI (Aldrich), $0.01 \mathrm{M} \mathrm{I}_{2}$ (Aldrich), and $0.2 \mathrm{M}$ $\mathrm{TBABF}_{4}$ in acetonitrile.

Cyclic voltammograms were performed with $\mathrm{CH}$ Instruments CHI 900 Electrochemical Analyzer using a platinum disk working electrode and silver ion working electrode in acetonitrile with $0.20 \mathrm{M} \mathrm{TBABF} 4$ at $100 \mathrm{mV} / \mathrm{s}$. Photoelectrochemical measurements were performed with a CH Instruments CHI 1202 Electrochemical Analyzer interfaced with a Jovin Yvon Spex FluoroLog-3 fluorimeter to obtain solar cell data. The fluorimeter had the slits set such that the light intensity was $100 \mathrm{~mW} / \mathrm{cm}^{2}$, and an AM 1.5 solar filter was used.

\section{Results and Discussion}

FTO Modification. Steady-state current density, $J$, versus potential, $E$, measurements were performed in the dark on DSSCs featuring nanoparticle $\mathrm{TiO}_{2}$ electrodes in contact with an acetonitrile solution containing $\mathrm{Fc}^{+}, \mathrm{Fc}$, and $\mathrm{TBABF}_{4}$. Figure 1a shows that high dark-current densities are obtained when a nanoparticle $\mathrm{TiO}_{2}$ film is deposited directly on the FTO substrate (blue line) without a blocking layer, similar to the report by Gregg et al. ${ }^{14}$ Spray pyrolysis is often used to deposit a compact layer of $\mathrm{TiO}_{2}$ on the FTO substrate before deposition of a $\mathrm{TiO}_{2}$ nanoparticle film; however, layers formed by pyrolysis typically lack uniformity and are relatively difficult to prepare in pinholefree fashion. ${ }^{14,43}$ Here we used 400 ALD cycles to assemble a $\sim 14 \mathrm{~nm} \mathrm{TiO}_{2}$ blocking layer on the FTO substrate, just prior to deposition of the $\mathrm{TiO}_{2}$ nanoparticle film. Figure 1a shows the greatly reduced dark-current density (black line) resulting from the effective passivation of the FTO. Also shown is the increased photocurrent density (black line; Figure 1b) and the introduction of diode-like behavior-behavior attributable to elimination of shunting by the otherwise exposed FTO. (Given its effectiveness, a $\sim 14 \mathrm{~nm}$ blocking layer of $\mathrm{TiO}_{2}$ was employed in all further devices described herein.) Notably, even after elimination of shunting by FTO, the photocurrent density is low $\left.(\sim 0.1 \mathrm{~mA} \mathrm{~cm})^{-2}\right)$. This behavior implies that the overwhelming majority of injected electrons are being intercepted by ferrocenium before they can be captured by the

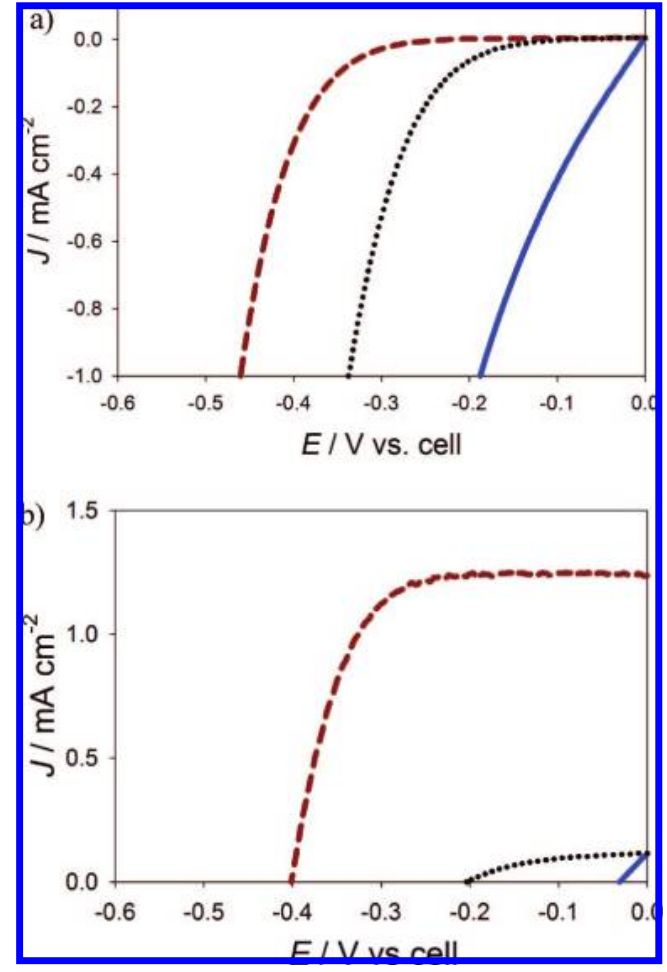

Figure 1. Current density, $J$, vs applied potential, $E$, for nanoparticle $\mathrm{TiO}_{2}$ deposited directly on the FTO substrate (blue, solid), with a $\sim 14$ $\mathrm{nm} \mathrm{TiO}$ blocking layer (black, dotted), and with both a blocking layer and 1 ALD cycle of $\mathrm{Al}_{2} \mathrm{O}_{3}$ (red, dash): (a) in the dark and (b) under 1 sun illumination.

underlying current collector (i.e., the interception rate greatly exceeds the charge-collection rate).

Semiconductor Modification: Single Layers. In order to control the loss of injected electrons via interception by $\mathrm{Fc}^{+}$, we coated the entire $\mathrm{TiO}_{2}$ surface with thin layers of $\mathrm{Al}_{2} \mathrm{O}_{3}$. Figure 1a shows that a single ALD cycle of $\mathrm{Al}_{2} \mathrm{O}_{3}$ decreases the dark-current density by more than 1 order of magnitude at a given potential. It is important to note that, since ALD is a self-limiting film-fabrication method, one cycle will produce only a single monolayer (or less) of $\mathrm{Al}_{2} \mathrm{O}_{3}$. Measurements of thicker layers of $\mathrm{Al}_{2} \mathrm{O}_{3}$ as a function of number of ALD cycles yield $1.1 \AA$ A/cycle under the conditions used, in good accordance with literature reports. ${ }^{28,30,33}$

Figure 1b shows the dramatic enhancement in photovoltage brought about by a single ALD cycle of $\mathrm{Al}_{2} \mathrm{O}_{3}$. As noted above, there are (in principle) three mechanisms by which an $\mathrm{Al}_{2} \mathrm{O}_{3}$ layer can improve the photovoltage of a DSSC. The layer can introduce a surface dipole that shifts the bands negatively, thereby producing an increased open-circuit photovoltage, $V_{\text {oc. }}{ }^{17,29}$ Previous studies of $\mathrm{Al}_{2} \mathrm{O}_{3}$ coatings on $\mathrm{TiO}_{2}$ showed increases in $V_{\text {oc }}$ of $\sim 50 \mathrm{mV},{ }^{28,29,44,45}$ much less than the $\sim 200$ $\mathrm{mV}$ observed here. It is unlikely that $\mathrm{Al}_{2} \mathrm{O}_{3}$ coatings will shift the bands substantially more in our system than in previously studied systems. Further, a negative shift of the conduction band is unlikely to cause a decrease in the interception rate constant (in fact, it should increase it) or increase injection (in fact, it should decrease it)-behavior that would be necessary in order to explain the observed large increase in short-circuit current density, $J_{\text {sc }}$. We therefore discount shifting of the band edge as a significant contributor to the observed performance improvement.

$\mathrm{Al}_{2} \mathrm{O}_{3}$ can also act as a barrier to electron tunneling, thereby decreasing the rate (and rate constant) for interception of injected electrons by $\mathrm{Fc}^{+}$. At open circuit, the rate of electron injection 
necessarily equals the sum of the rates for recombination (with $\mathrm{dye}^{+}$) and interception (by the oxidized form of the shuttle). ${ }^{5}$ Ferrocene has been shown to reduce $\mathrm{N} 3^{+}$rapidly; thus, electron recombination with the oxidized dye is not expected to play a significant role in determining $V_{\mathrm{oc}}$ in this system. ${ }^{15}$ Under these conditions, the rates of injection and interception determine the steady-state electron concentration in the semiconductor and, therefore, its quasi-Fermi level. All else being equal, for each factor-of-ten decrease in the rate of interception, $V_{\text {oc }}$ should increase by $\gamma \cdot 59 \mathrm{mV}$-provided that electrons are transferred from the semiconductor's conduction band. ${ }^{24,28-30}(\gamma$ is the diode quality factor, and typically has a value between 1 and 1.5.) The observed $\sim 200 \mathrm{mV}$ increase in $V_{\text {oc }}$ implies a $2-3$ orderof-magnitude decrease in interception rate-a much more significant attenuation than achievable with a $1.1 \AA$ layer tunneling barrier. We conclude that tunneling-based attenuation is not responsible for the observed effects.

A third explanation is that interception at the naked electrode can occur via surface electronic states (sub-band-edge states) and that the $\mathrm{Al}_{2} \mathrm{O}_{3}$ coating passivates (or eliminates) these states. ${ }^{16,46}$ If the relevant surface states are localized states associated with incompletely or "incorrectly" coordinated titanium ions (e.g., titanium ions having a water or hydroxyl ligand in place of a bridging oxo ligand), a single exposure to the highly reactive trimethylaluminum vapor should serve to convert most or all such sites to ones having full oxo coordination. In the absence of other plausible explanations, we favor passivation as the primary explanation for the observed photovoltage enhancement.

In addition to increasing $V_{\mathrm{oc}}$, treatment of photoanodes with a single alumina ALD cycle very substantially increases the short-circuit current density (Figure 1b). The large increase stands in contrast to the results of previous studies. For example, for a DSSC based on $\mathrm{ZnO}$ nanorod arrays, even a single alumina deposition cycle (via ALD) led to somewhat smaller photocurrent densities. ${ }^{28}$ Other reports of the effects of formation of thin $\mathrm{Al}_{2} \mathrm{O}_{3}$ films (prepared by dip-coating) on $\mathrm{TiO}_{2}$ and $\mathrm{SnO}_{2}$ nanoparticles also document decreases in photocurrent densities. ${ }^{28,29,47,48}$ While one report does describe an increase of current density with an $\mathrm{Al}_{2} \mathrm{O}_{3}$ coating, the increase is modest ( $\sim 30 \%$ ) in comparison to the $\sim 12$-fold increase observed here. ${ }^{24}$ In rationalizing the findings, it is tempting to focus on the details of photoelectrode fabrication and modification; however, the salient difference between the current study and the previous ones almost certainly is instead the use of $\mathrm{Fc}^{+/ 0}$ in place of $\mathrm{I}_{3}{ }^{-}$ $\mathrm{I}^{-}$. With the latter, interception is generally sufficiently slow that photoinjected electrons can be collected from throughout the porous photoelectrode with high efficiency. Hence, decreasing the rate of interception should not yield larger values for $J_{\text {sc. }} \cdot 49$

In contrast, with $\mathrm{Fc}^{+/ 0}$ as the shuttle, electron interception (at naked electrodes) is comparatively rapid and electrons can be efficiently collected only if they are injected close to the current-collection face of the photoelectrode. Expressed another way, under conditions of fast interception, the electron-diffusion distance is small in comparison to the overall electrode thickness. ${ }^{5}$ By slowing the $\mathrm{Fc}^{+}$interception rate, the alumina coating increases the distance over which injected electrons can be efficiently collected and thereby increases $J_{\mathrm{sc}}$. The results in Figure 1b suggest a greater than 12-fold increase in electrondiffusion distance (depending on the wavelength-variable details of light penetration in the DSSC), which thus implies a decrease in interception rate constant (at short circuit) of at least $\sim 140$ fold $\left(\sim 12^{2}\right)$.

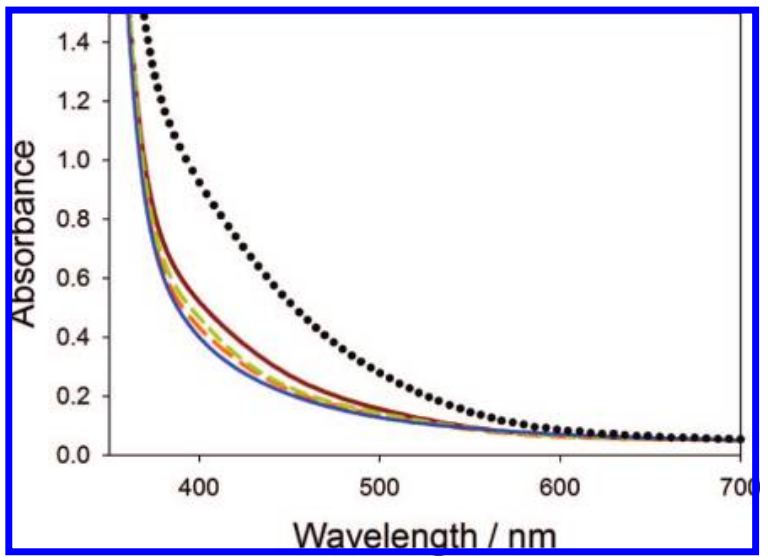

Figure 2. UV-visible absorption spectra of catechol on $\mathrm{TiO}_{2}$ nanoparticle electrodes with 0 (black, dotted), 1 (red, solid), 2 (yellow, small dash), and 3 (orange, large dash) ALD cycles of $\mathrm{Al}_{2} \mathrm{O}_{3}$. For comparison, the spectrum of bare $\mathrm{TiO}_{2}$ (blue) is also shown.

Semiconductor Modification: Multiple Layers. Additional layers of $\mathrm{Al}_{2} \mathrm{O}_{3}$ were deposited on the nanoparticles in order to further investigate and optimize the effect of the coatings. As a prelude to photovoltaic characterization, several naked and ALD-modified electrodes (all lacking dye) were soaked in catechol-containing solutions. After rinsing, the electronic absorption spectra of the electrodes were recorded. As shown in Figure 2, the spectrum of the alumina-free electrode displays a poorly resolved (but easily observed) feature, in the blue part of the spectrum, which is characteristic of catechol-titanium charge-transfer complexes. ${ }^{31,50}$ The absorbance is greatly diminished, but still detectable, for an electrode subjected to one ALD cycle of $\mathrm{Al}_{2} \mathrm{O}_{3}$ modification-establishing that a single deposition cycle produces slightly less than a full monolayer of alumina (i.e., some titanium sites remain exposed). The usual interpretations in the ALD literature of such behavior center on the relative footprints of the surface-adsorbed precursor molecules versus product species. ${ }^{33}$ More generally, the precursor/product size differential (as well as other effects) accounts for the common observation that the "per cycle" rate of film deposition is less than expected for full monolayer deposition. Returning to the case at hand, we note that many shuttle molecules (including ferrocenium) are larger than catechol; thus, the surface may well be effectively pinhole-free with even a single ALD cycle. The absorption band disappears (within experimental uncertainty) with additional $\mathrm{Al}_{2} \mathrm{O}_{3}$ layers.

Turning to cell behavior, Figure 3 a shows that dark-current densities progressively decrease, as expected, with increasing alumina-coating thickness. Figure $3 b$ illustrates the $J-E$ response, under 1 sun illumination, for a series of $\mathrm{Fc}^{+/ 0}$-containing DSSCs featuring photoelectrodes coated with alumina via one, two, three, four, or five ALD cycles. While the first cycle produces large increases in $J_{\mathrm{sc}}, V_{\mathrm{oc}}$, and $F F$ (and thus $\eta$ ), additional cycles yield only small additional increases in $V_{\mathrm{oc}}$, as expected from the smaller dark-current densities displayed in Figure 3a. The photocurrent density, on the other hand, sharply drops as the coating thickness increases. (See Supporting Information for numerical tabulations of $J_{\mathrm{sc}}, V_{\mathrm{oc}}, F F$, and $\eta$ as a function of extent of alumina modification.) While consistent with other studies involving $\mathrm{I}_{3}{ }^{-} / \mathrm{I}^{-}, 28,30$ this result is striking because it implies that injection is slowed sufficiently to diminish substantially the dye-injection yield. ${ }^{51}$ Unity charge-injection efficiency requires that even the slowest part of injection dynamics be faster than competing processes. Haque et al. have reported that a significant portion (10\%) of the highly dispersive 


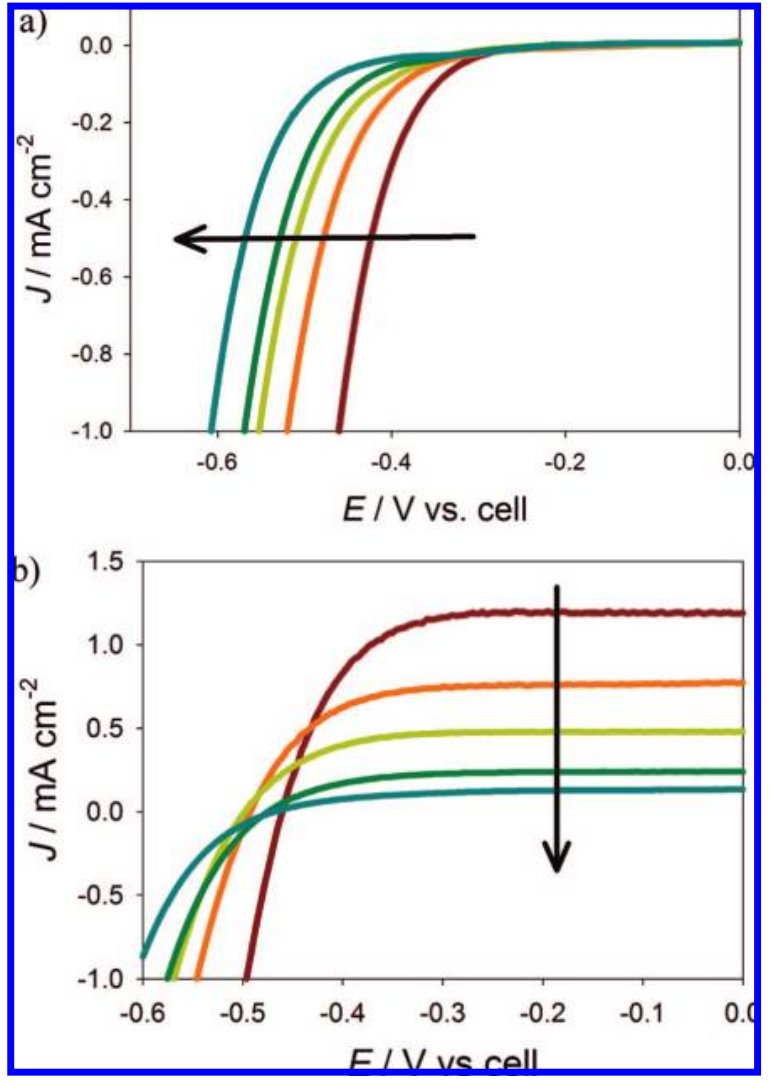

Figure 3. Current density, $J$, vs applied potential, $E$, for nanoparticle $\mathrm{TiO}_{2}$ electrodes coated with 1 (red), 2 (orange), 3 (yellow), 4 (green), and 5 (blue) ALD cycles of $\mathrm{Al}_{2} \mathrm{O}_{3}$ (a) in the dark and (b) under 1 sun illumination. The black arrow highlights the trend of increasing $\mathrm{Al}_{2} \mathrm{O}_{3}$.

injection kinetics for photoexcited $\mathrm{N} 719$ on nanocrystalline $\mathrm{TiO}_{2}$ occurs on time scales $>1 \mathrm{~ns} .{ }^{52}$ It has further been shown that the electron injection kinetics depends on the dye used, ${ }^{52,53}$ electrolyte composition, ${ }^{52,54}$ and surface treatment. ${ }^{31}$ It is, thus, difficult to make accurate comparisons of electron injection in our system of $\mathrm{N} 3$ on $\mathrm{Al}_{2} \mathrm{O}_{3}$ coated $\mathrm{TiO}_{2}$ in contact with a ferrocene electrolyte. We want to point out, however, that previous measurements of slow electron injection can account for the diminished photocurrent densities with increasing barrier layer thickness reported herein. Haque et al. further emphasized, despite the ultrafast nature of injection for a fraction of the dye molecules, little room remains for optimization of the overall injection dynamics ${ }^{55}-\mathrm{a}$ conclusion that is borne out here.

Previous studies have shown that $\mathrm{Al}_{2} \mathrm{O}_{3}$ coated surfaces produce slightly higher dye (N3) loadings in comparison with bare $\mathrm{TiO}_{2}{ }^{24,28}$ After the first ALD cycle of $\mathrm{Al}_{2} \mathrm{O}_{3}$, the surface is predominately composed of $\mathrm{Al}_{2} \mathrm{O}_{3}$, and subsequent cycles should not change the surface and, thus, dye coverage. This is consistent with our observation that dye loading was essentially constant for all electrodes studied, and any slight variation cannot account for any of the trends reported herein.

Figure 4a shows the results of open-circuit voltage decay measurements of $\mathrm{TiO}_{2}$ photoelectrodes coated with 1,3 , and 5 cycles of $\mathrm{Al}_{2} \mathrm{O}_{3}$. These measurements enable one to assess the kinetics of interception. ${ }^{56}$ Briefly, the voltage decays can be transformed into electron lifetimes, $\tau_{\mathrm{n}}$, according to ${ }^{56}$

$$
\tau_{\mathrm{n}}=\frac{k_{\mathrm{B}} T}{q}\left(\frac{\mathrm{d} V_{\mathrm{oc}}}{\mathrm{d} t}\right)^{-1}
$$

Recall that the lifetime of the electron is simply the amount of time the electron survives before being intercepted (assuming

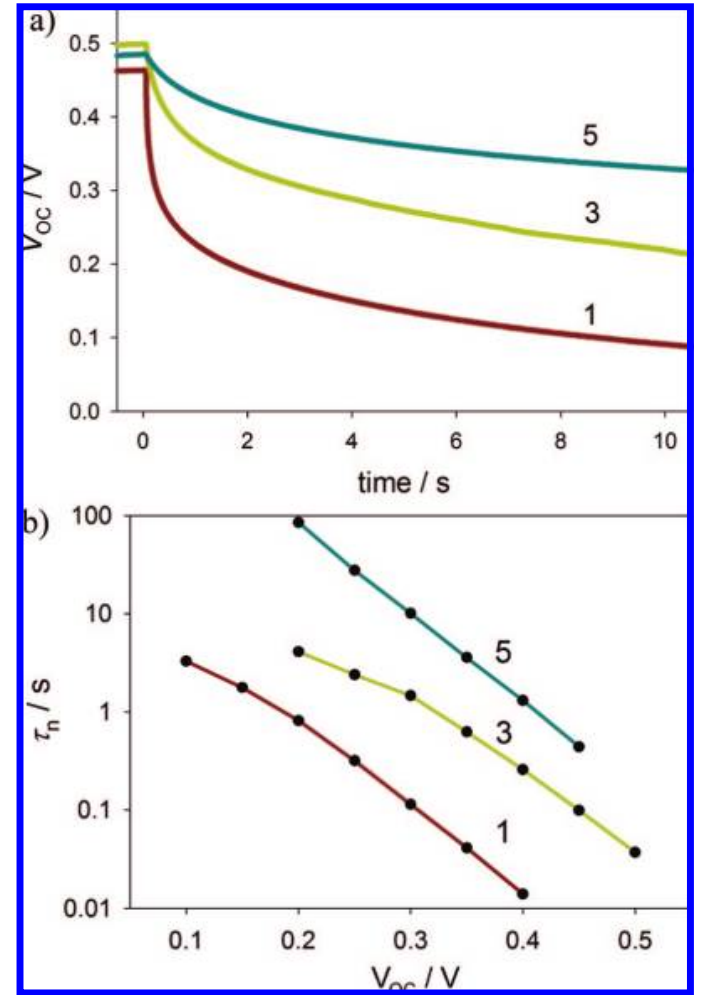

Figure 4. (a) Open-circuit voltage decay and (b) lifetimes of DSSCs using nanoparticle $\mathrm{TiO}_{2}$ electrodes coated with 1 (red), 3 (yellow), and 5 (blue) ALD cycles of $\mathrm{Al}_{2} \mathrm{O}_{3}$.

recombination with $\mathrm{dye}^{+}$can be neglected), so it is inversely proportional to the interception rate constant (provided that the reaction is first order in electrons; see below). Figure 4b shows the electron lifetime as a function of voltage for the samples examined in Figure 4a. The observed exponential variation of the lifetime with open-circuit voltage is consistent with an interfacial charge-transfer pathway that avoids surface states and instead proceeds only through the conduction band. ${ }^{16,56}$ The lifetime increases, at a given voltage, for each additional cycle of $\mathrm{Al}_{2} \mathrm{O}_{3}$ (Figure $4 \mathrm{~b}$ ). The $\mathrm{Al}_{2} \mathrm{O}_{3}$ layers thus appear to act as effective barrier layers for the interfacial electron-transfer reactions.

A plot of the open circuit photovoltage versus the log of the incident light intensity has a slope of $77 \mathrm{mV}$ per decade (see Supporting Information). This near-ideal photodiode behavior establishes that the interception reaction is indeed first order in electron concentration (making the interception rate constant proportional to $\left.1 / \tau_{\mathrm{n}}\right){ }^{49,57}$ If the $\mathrm{ALD}$-formed $\mathrm{Al}_{2} \mathrm{O}_{3}$ behaves as a simple tunneling barrier, the electron interception rate should decrease exponentially with layer thickness, $r$. A plot of $\ln (1 /$ $\tau_{\mathrm{n}}$ ) vs $r$ should be linear with a slope of $-\beta$, where $\beta$ is the usual tunneling attenuation parameter. Figure 5 shows a plot of $\ln \left(1 / \tau_{\mathrm{n}}\right)$ vs number of $\mathrm{Al}_{2} \mathrm{O}_{3}$ deposition cycles at the same voltage, $V_{\mathrm{oc}}=0.35 \mathrm{~V}$. (The result of the analysis is relatively insensitive to the voltage used; however, a comparatively high voltage was chosen because it is close to the maximum power point and because the plots deviate from linearity at low voltages). A straight-line fit to the data yields a slope of -1.1 / cycle. Each ALD cycle deposits $\sim 1.1 \AA$ of $\mathrm{Al}_{2} \mathrm{O}_{3}$, thus yielding $\beta \approx 1 \AA^{-1}-$ a reasonable value for a high-barrier material such as alumina. The exponential dependence of $1 / \tau_{\mathrm{n}}$ with distance $\left(\mathrm{Al}_{2} \mathrm{O}_{3}\right.$ cycles $)$ can be taken as further evidence that interception occurs via the conduction band. 


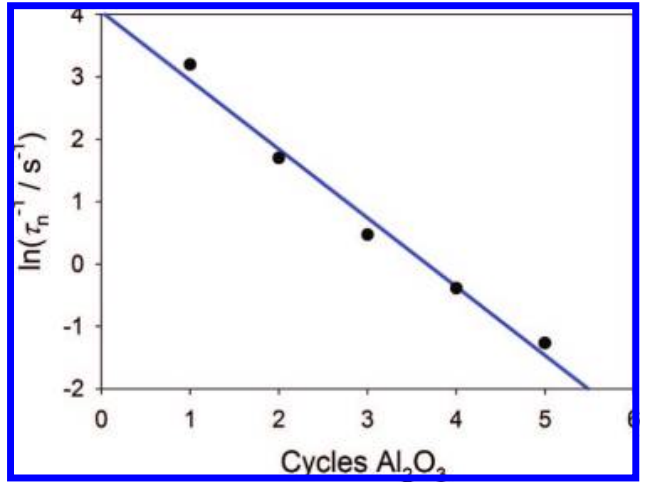

Figure 5. Plot of the logarithm of the interception rate $\left(1 / \tau_{\mathrm{n}}\right)$ at $V_{\mathrm{oc}}=$ $0.35 \mathrm{~V}$ as a function of number of $\mathrm{Al}_{2} \mathrm{O}_{3}$ deposition cycles.

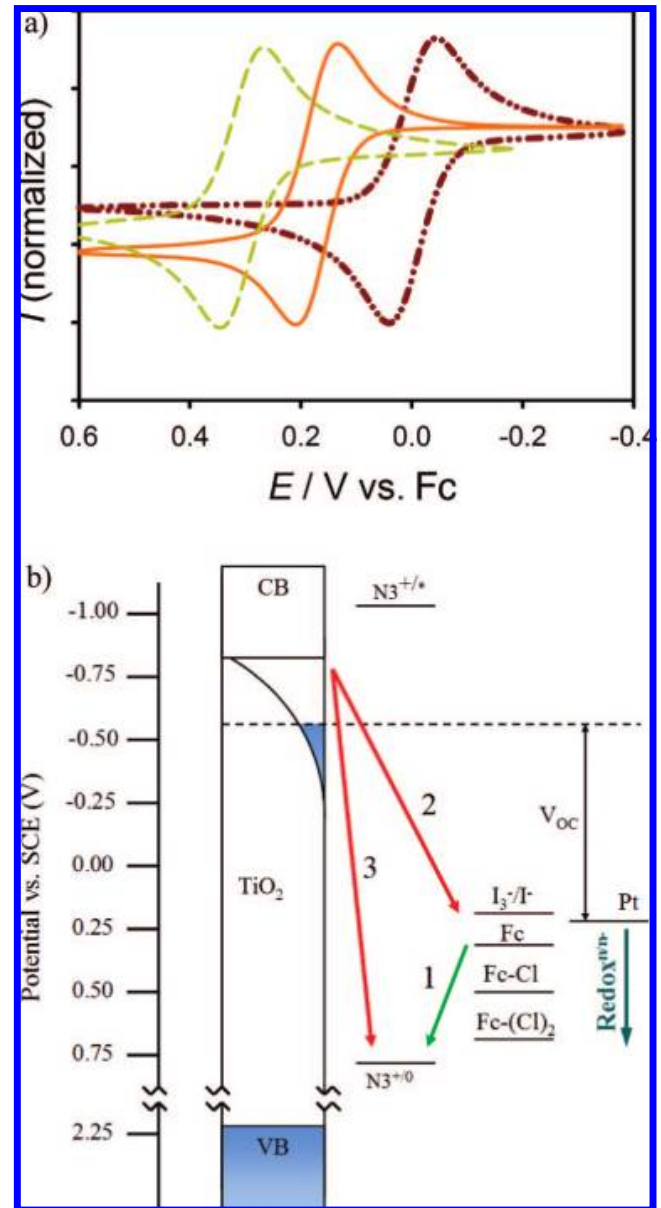

Figure 6. (a) Cyclic voltammograms of $\mathrm{Fc}$ (red, dot-dot-dash), $\mathrm{Fc}-\mathrm{Cl}$ (orange, solid line), and $\mathrm{Fc}-(\mathrm{Cl})_{2}$ (yellow, dash). (b) Approximate energy diagram of a DSSC sensitized with N3, showing the potentials of the ferrocene-based redox. The arrows show the processes affected (directly or indirectly) by changing redox couples: (1) regeneration, (2) interception, and (3) recombination.

Derivatives of Ferrocenium/Ferrocene as Redox Shuttles. In order to increase the photovoltage, $\mathrm{Fc}-\mathrm{Cl}^{+/ 0}$ and $\mathrm{Fc}(\mathrm{Cl})_{2}{ }^{+/ 0}$ were employed in place of $\mathrm{Fc}^{+/ 0}$ as shuttles/regenerators. As illustrated by the cyclic voltammograms in Figure 6a, the redox couples are reversible, with the formal potentials of the chloroand dichloro-derivatives being 0.17 and $0.31 \mathrm{~V}$ more positive, respectively, than the parent redox couple, as expected. ${ }^{58}$ If the $\mathrm{TiO}_{2}$ quasi-Fermi level remains constant, the use of the chlorinated ferrocenes should result in improvements in opencircuit photovoltage of 0.17 and $0.31 \mathrm{~V}$ for $\mathrm{Fc}_{-}-\mathrm{Cl}^{+/ 0}$ and $\mathrm{Fc}(\mathrm{Cl})_{2}{ }^{+/ 0}$, respectively, compared to $\mathrm{Fc}^{+/ 0}$ (Figure 6b). Deviation

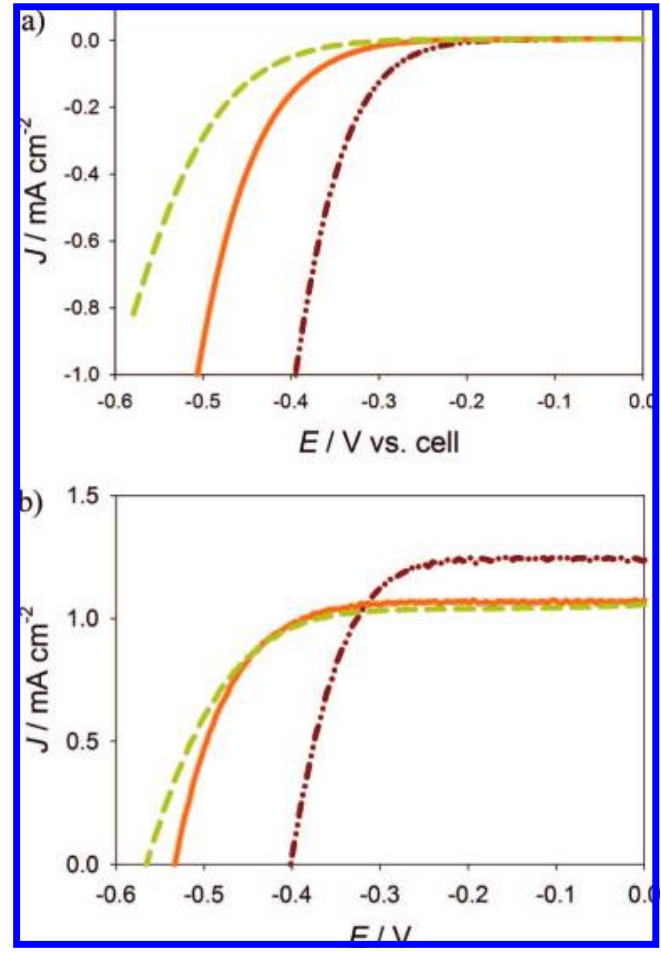

Figure 7. $J-E$ curves for DSSCs employing Fc (red, dot-dot-dash), $\mathrm{Fc}-\mathrm{Cl}$ (orange, solid), and $\mathrm{Fc}-(\mathrm{Cl})_{2}$ (yellow, dash) redox shuttles: (a) in the dark and (b) under 1 sun illumination. The photoelectrodes in each case have been coated with 1 ALD cycle of alumina.

from these values, however, provides insight into the relative rates of recombination and interception.

Figure 7a compares dark-current densities for DSSCs containing $\mathrm{TiO}_{2}$ nanoparticle photoelectrodes coated with 1 cycle of $\mathrm{Al}_{2} \mathrm{O}_{3}$ and employing $\mathrm{Fc}^{+/ 0}, \mathrm{Fc}-\mathrm{Cl}^{+/ 0}$, or $\mathrm{Fc}-(\mathrm{Cl})_{2}^{+/ 0}$ as a redox shuttle. The dark-current density is much lower at a given potential for $\mathrm{Fc}_{-}-\mathrm{Cl}^{+/ 0}$, compared to $\mathrm{Fc}^{+/ 0}$, and even lower for $\mathrm{Fc}-(\mathrm{Cl})_{2}{ }^{+/ 0}$. Since the cells are two-electrode systems and the potentials are referenced to solution potentials that differ by $\sim 160 \mathrm{mV}$ per chlorine, the decreasing dark-current density (while good) is somewhat misleading. Correcting for the differences in reference potential, we find that dark-current density increases at a given electrode potential as ferrocenium is replaced by chloroferrocenium and then 1,1'-dichloroferrocenium. If the intercepted electrons indeed transfer from the conduction band, the larger dark-current density implies that the interception rate constant increases with driving force (assuming that the conduction band energy is essentially constant). Thus, the interception reactions appear to be occurring in the Marcus normal region-a surprising result given estimated driving forces (Figure 6b) of ca. 1.1-1.4 eV. These observations in turn imply reorganization energies of greater than $1.4 \mathrm{eV}$ for interception. While we have no explanation for the (apparently) extraordinarily large reorganization energies, we note that studies of back-ET to electrostatically bound dye molecules on $\mathrm{SnO}_{2}$ surfaces also seemed to show anomalously large reorganization energies. ${ }^{59}$

Returning to DSSC behavior, Figure $7 \mathrm{~b}$ compares photovoltaic responses for cells containing $\mathrm{Fc}^{+/ 0}, \mathrm{Fc}^{-} \mathrm{Cl}^{+/ 0}$, or $\mathrm{Fc}-(\mathrm{Cl})_{2}{ }^{+/}$ o. Similar short-circuit current densities are observed for the three cells, albeit decreasing slightly as the shuttle redox potential increases. The open-circuit photovoltage, on the other hand, increases as the shuttle formal potential increases, although by less than the shifts in formal potential. These results indicate that the quasi-Fermi level lowers (i.e., moves to less negative 


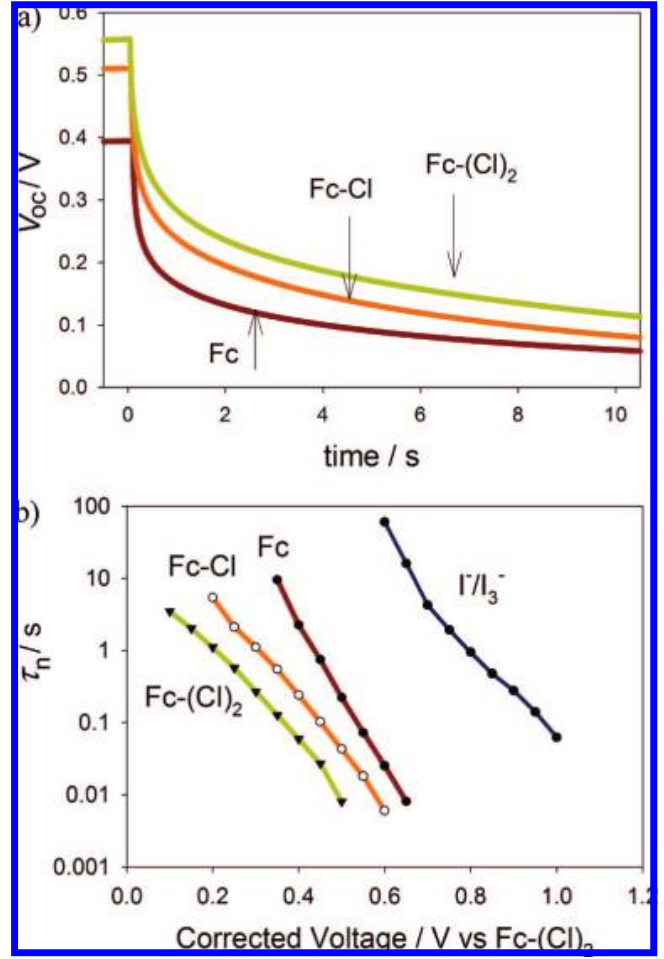

Figure 8. (a) Open-circuit voltage decay and (b) lifetimes of DSSCs employing $\mathrm{Fc}^{+/ 0}$ (red), $\mathrm{Fc}-\mathrm{Cl}^{+/ 0}$ (orange), and $\mathrm{Fc}-(\mathrm{Cl})_{2}^{+/ 0}$ (yellow) redox shuttles. The lifetimes are normalized to a common reference potential. The lifetime vs corrected voltage of a standard $\mathrm{I}^{-} / \mathrm{I}_{3}{ }^{-}$ electrolyte (green) is also shown for comparison. The photoelectrodes in each case have been coated with 1 ALD cycle of alumina.

potentials on the electrochemical scale; see Figure $6 \mathrm{~b}$ ) in the order $\mathrm{Fc}>\mathrm{Fc}-\mathrm{Cl}>\mathrm{Fc}-(\mathrm{Cl})_{2}$. This trend is consistent with the trend in dark-current densities.

Closer comparisons reveal that the increase in $V_{\text {oc }}$ for the cell employing $\mathrm{Fc}-(\mathrm{Cl})_{2}{ }^{+/ 0}$ versus the cell employing $\mathrm{Fc}-\mathrm{Cl}^{+/ 0}$ is slightly less than expected based on the relative dark-current densities. Recall that the dark current is a measure of the rate of the shuttle interception reaction (only), whereas $V_{\text {oc }}$ is responsive to both shuttle interception and dye recombination. Since regeneration is anticipated to be slower with $\mathrm{Fc}-(\mathrm{Cl})_{2}$ (due to the lower reaction driving force), we tentatively attribute the somewhat smaller increase in $V_{\mathrm{oc}}$ with the $\mathrm{Fc}-(\mathrm{Cl})_{2}$ shuttle to electron loss via recombination with the oxidized dye. In principle, increasing the concentration of $\mathrm{Fc}-(\mathrm{Cl})_{2}$ should overcome the regeneration problem. Our attempts in this regard were hampered, however, by the relatively poor solubility of $\mathrm{Fc}-(\mathrm{Cl})_{2}$ in acetonitrile (i.e., $<0.2 \mathrm{M}$ ).

The performance of the most efficient DSSCs is known to be influenced by solution additives, most notably lithium salts and tert-butylpyridine. We therefore examined the effects of additives here. For $\mathrm{LiClO}_{4}$ addition, the chief effect was a decrease of $\sim 70 \mathrm{mV}$ in $V_{\text {oc }}$ with all ferrocene shuttles (see Supporting Information), a finding that is consistent with a systematic lowering of the conduction band edge of the $\mathrm{TiO}_{2}$, as has been discussed in detail elsewhere. ${ }^{60,61}$ Attempts to introduce tert-butylpyridine resulted in fairly rapid decomposition of the ferrocenium species, preventing photovoltaic measurements. The instability of the ferrocenium species may be a limitation to optimization and practical use of ferrocenes as redox shuttles in DSSCs.

Figure 8a compares open-circuit voltage-decay transients of DSSCs with $\mathrm{Fc}^{+/ 0}, \mathrm{Fc}-\mathrm{Cl}^{+/ 0}$, or $\mathrm{Fc}-(\mathrm{Cl})_{2}{ }^{+/ 0}$ couples as redox shuttles. The rate of voltage decay (interception) decreases at a given open-circuit voltage with decreasing potential for the redox shuttle. This result is in agreement with the dark-current density measurements as expected, since they are both measurements of the rates of interception. In order to compare the relative interception rate constants, at the same electrode quasi-Fermi level, the voltages are corrected for the different solution potentials to the $\mathrm{Fc}-(\mathrm{Cl})_{2}{ }^{+/ 0}$ couple's potential. The corrected lifetimes are shown in Figure $8 \mathrm{~b}$. The corrected lifetimes decrease in the order $\mathrm{Fc}>\mathrm{Fc}-\mathrm{Cl}>\mathrm{Fc}-(\mathrm{Cl})_{2}$, which is in agreement with the ordering of (corrected) dark-current densities as described above.

Included for comparison in Figure $8 \mathrm{~b}$ are electron-lifetime data for a DSSC employing the $\mathrm{I}_{3}{ }^{-} / \mathrm{I}^{-}$redox shuttle $(0.60 \mathrm{M}$ TBAI, $0.01 \mathrm{M} \mathrm{I}_{2}, 0.20 \mathrm{M} \mathrm{TBABF}_{4}$ in acetonitrile), also corrected to $\mathrm{Fc}-(\mathrm{Cl})_{2}$ 's solution potential by shifting the lifetimes by 0.41 $\mathrm{V}$. The slopes of semilog plots of $\tau_{\mathrm{n}}$ vs $V_{\mathrm{oc}}$ are similar for the various shuttles. At a given potential, however, the electron lifetime in the presence of $\mathrm{I}_{3}{ }^{-} / \mathrm{I}^{-}$is $>10^{4}$ longer than with ferrocenenium/ferrocene. Since (as pointed out above) the lifetime is inversely proportional to the interfacial electrontransfer rate constant, $k_{\text {et }}$, this implies that $k_{\text {et }}$ for ferrocene is $>10^{4}$ larger than for $\mathrm{I}_{3}^{-} / \mathrm{I}^{-}$.

Issues in Building Efficient DSSCs Based on Alternative Redox Couples. As noted above, the main benefits of the very small $k_{\text {et }}$ value for $\mathrm{I}_{3}^{-} / \mathrm{I}^{-}$are as follows: (a) long lifetimes for injected electrons, resulting in highly efficient current collection over long distances and (b) small dark currents, resulting in high quasi-Fermi levels (necessary for good photovoltages). We consider issue (a) first: Evaluation of short-circuit photocurrents for cells containing $\mathrm{Fc}^{+/ 0}$ as the shuttle/regenerator (Figure 3) suggests that electrode treatment with 1 ALD cycle of alumina increases the charge-collection distance by about 1 order of magnitude. Extension of the charge-collection depth by another factor of 20 or so will be necessary to achieve near-quantitative current collection with the present (or a similarly absorbing) chromophore. In principle, this can be achieved by slowing the interception rate by another $2-2.5$ orders of magnitude. From Figure 5, we conclude that treating an electrode with 7 or 8 ALD cycles of alumina should yield the needed rate decrease. To sustain good injection yields, however, it will be necessary to: (i) extend the photoexcited state lifetime by $2-2.5$ orders of magnitude or (ii) eliminate the slow-injecting population of dye molecules and replace the population with fast-injecting dyes. Recent work by Abrahamsson and co-workers illustrates how excited-state lifetimes can be greatly extended. ${ }^{62}$ Work by Wenger and co-workers points to dye aggregation as the source of multiphasic injection kinetics and suggests that, if aggregation can be prevented, the problematic slow-injecting population will be eliminated. ${ }^{63}$ An alternative approach would be to use dyes with much higher extinction coefficients, thereby enabling thinner photoelectrodes to be used and allowing a greater fraction of dyeinjected electrons to be collected. ${ }^{7,64}$ Finally, faster electron transport would improve the collection efficiency. ${ }^{5,65-67}$

The second challenge, issue (b), is to decrease dark currents further and thereby raise the quasi-Fermi level at the photoelectrode (anode) and increase the cell photovoltage. Replacing $\mathrm{I}_{3}{ }^{-} / \mathrm{I}^{-}$by $\mathrm{Fc}-(\mathrm{Cl})_{2}{ }^{+/ 0}$ offers a ca. $0.41 \mathrm{~V}$ shift in the potential of the dark electrode (cathode). However, the advantageous shift is more than offset by lowering of the quasi-Fermi level at the photoelectrode. For the cells examined here, each factor-of-10 reduction in dark current at the anode should raise the quasiFermi level and increase $V_{\mathrm{oc}}$ by about $70 \mathrm{mV}$ (provided that there is no decrease in injection yield). Since the dark current 
scales as the electrode surface area, any reduction in surface area (made possible, for example, by employing higherextinction chromophores) should translate into higher $V_{\text {oc }}$ values. Similarly, the use of thicker barrier layers (Figure 5) should increase photovoltages (again, assuming that dyes can be found that do not suffer losses in injection yield upon introduction of the barrier layers). If the number of ALD cycles could be increased from 1 to 8 , with retention of high injection yields as discussed above, $V_{\text {oc }}$ values should increase by ca. 170 to 200 $\mathrm{mV}$. Clearly, a challenge going forward will be to design dyes that can satisfy the injection-yield requirements. An additional strategy would be to use the dye layer itself to block access of the shuttle to the underlying photoelectrode. The comparatively small sizes of iodide and triiodide make this challenging; however, such an approach might well prove effective with appropriately designed dyes and a sterically demanding redox shuttle. This is a focus of ongoing work. ${ }^{68}$ Finally, it is important to note that, while faster electron collection will improve the current collection efficiency, it will not improve the open-circuit photovoltage.

\section{Conclusions}

Atomic layer deposition of a $\sim 14 \mathrm{~nm} \mathrm{TiO}_{2}$ layer on FTO prior to nanoparticle addition is an effective measure for defeating redox-shuttle shunting by the current collector in DSSCs. Highly controlled deposition of alumina layers on the $\mathrm{TiO}_{2}$ nanoparticles defining the photoanode is also beneficial in DSSCs featuring fast redox shuttles, but for different reasons. The major effect of the first cycle of alumina is to passivate surface states, resulting in dramatic improvement in photovoltaic performance when $\mathrm{Fc}^{+/ 0}$ is employed as the redox shuttle. Subsequent alumina layers act as tunneling barrier layers. The inverse of the electron lifetime was found to decrease exponentially with ALD cycles (i.e., distance), consistent with electron tunneling, allowing for an estimation of $\beta \approx 1 \AA^{-1}$. The barrier layers also slow down electron injection, however, resulting in diminishing photocurrent densities and diminishing energy conversion overall efficiency with extension of the deposition beyond a single alumina ALD cycle.

The use of chlorine-derivatized ferrocene couples shifts the potential at the dark electrode (at open circuit) by as much as $310 \mathrm{mV}$, relative to underivatized ferrocene. About one-half of the $310 \mathrm{mV}$ shift is captured as increased open-circuit (cell) photovoltage, indicating that the quasi-Fermi level at the illuminated photoelectrode lowers (i.e., shifts to less negative potential on an electrochemical scale) when $\mathrm{Fc}^{+/ 0}$ is replaced by $\mathrm{Fc}-(\mathrm{Cl})_{2}^{+/ 0}$. Intermediate behavior is seen with $\mathrm{Fc}-\mathrm{Cl}^{+/ 0}$ as the redox shuttle. Consistent with these observations, rates for interception of injected electrons were found to increase in the order $\mathrm{Fc}^{+}<\mathrm{Fc}-\mathrm{Cl}^{+}<\mathrm{Fc}-(\mathrm{Cl})_{2}{ }^{+}$, indicating that the interception reaction occurs in the Marcus normal region. Successful collection of the majority of photoinjected electrons, in cells of this kind, will require that interception rates be diminished by roughly 2 orders of magnitude. Further diminution (beyond ca. $10^{2}$ ) is not anticipated to improve photocurrents but should improve photovoltages. We suggest that further progress in this area may be achievable be focusing on dye properties that are not of great significance for DSSCs that employ standard $\mathrm{I}_{3}{ }^{-} / \mathrm{I}^{-}$electrolytes. Among the desired dye properties are the following: (a) ultrafast injection dynamics (at naked electrodes), (b) uniform injection dynamics, (c) higher extinction coefficients, and (d) ability to block contact between large shuttle molecules and the photoelectrode.
Acknowledgment. We gratefully acknowledge BP Solar and the Basic Energy Sciences Program, Office of Science, U.S. Dept. of Energy (Grant No. DE-FG87ER13808) for financial support of our work.

Supporting Information Available: Supplemental plots of $J_{\text {sc }}, V_{\text {OC }}, F F$, and $\eta$ for a series of $\mathrm{TiO}_{2}$ nanoparticle DSSCs with $0-5$ ALD cycles of $\mathrm{Al}_{2} \mathrm{O}_{3}$ in contact with $\mathrm{Fc}$, open circuit photovoltage vs. incident light intensity, $J-E$ curves for DSSCs employing $\mathrm{Fc}, \mathrm{Fc}-\mathrm{Cl}$, and $\mathrm{Fc}-(\mathrm{Cl})_{2}$ with $0.03 \mathrm{M} \mathrm{Li}^{+}$, and incident photon-to-current efficiency (IPCE) for DSSCs employing $\mathrm{Fc}, \mathrm{Fc}-\mathrm{Cl}$, and $\mathrm{Fc}-(\mathrm{Cl})_{2}$ with $0.03 \mathrm{M} \mathrm{Li}^{+}$are available as Supporting Information. This material is available free of charge via the Internet at http://pubs.acs.org.

\section{References and Notes}

(1) Nazeeruddin, M. K.; De Angelis, F.; Fantacci, S.; Selloni, A.; Viscardi, G.; Liska, P.; Ito, S.; Takeru, B.; Gratzel, M. G. J. Am. Chem. Soc. 2005, 127, 16835-16847.

(2) Nazeeruddin, M. K.; Kay, A.; Rodicio, I.; Humphrybaker, R.; Muller, E.; Liska, P.; Vlachopoulos, N.; Gratzel, M. J. Am. Chem. Soc. 1993, 115, 6382-6390.

(3) Gratzel, M. Inorg. Chem. 2005, 44, 6841-6851.

(4) Chiba, Y.; Islam, A.; Watanabe, Y.; Komiya, R.; Koide, N.; Han, L. Y. Jpn. J. Appl. Phvs., Part 2 2006, 45, L638-L640.

(5) Martinson, A. B. F.; Hamann, T. W.; Pellin, M. J.; Hupp, J. T. Chem.-Eur. J. 2008, 14, 4458-4467.

(6) Nusbaumer, H.; Zakeeruddin, S. M.; Moser, J. E.; Gratzel, M. Chem.-Eur. J. 2003, 9, 3756-3763.

(7) Hamann, T. W.; Jensen, R. A.; Martinson, A. B. F.; Van Ryswyk, H.; Hupp, J. T. Energy Environ. Sci. 2008, 1, 66-78.

(8) Kuciauskas, D.; Freund, M. S.; Gray, H. B.; Winkler, J. R.; Lewis, N. S. J. Phvs. Chem. B 2001, 105, 392-403.

(9) Sauve, G.; Cass, M. E.; Doig, S. J.; Lauermann, I.; Pomykal, K.; Lewis, N. S. J. Phvs. Chem. B 2000, 104, 3488-3491.

(10) Clifford, J. N.; Palomares, E.; Nazeeruddin, M. K.; Gratzel, M.; Durrant, J. R. J. Phvs. Chem. C 2007, 111, 6561-6567.

(11) O'Regan, B. C.; Lopez-Duarte, I.; Martinez-Diaz, M. V.; Forneli, A.; Albero, J.; Morandeira, A.; Palomares, E.; Torres, T.; Durrant, J. R. J. Am. Chem. Soc. 2008, 130, 2906-2907.

(12) Splan, K. E.; Massari, A. M.; Hupp, J. T. J. Phvs. Chem. B 2004, $108,4111-4115$

(13) Gregg, B. A. Coord. Chem. Rev. 2004, 248, 1215-1224.

(14) Gregg, B. A.; Pichot, F.; Ferrere, S.; Fields, C. L. J. Phvs. Chem. B 2001, 105, 1422-1429.

(15) Cazzanti, S.; Caramori, S.; Argazzi, R.; Elliott, C. M.; Bignozzi, C. A. J. Am. Chem. Soc. 2006, 128, 9996-9997.

(16) Fabregat-Santiago, F.; Garcia-Canadas, J.; Palomares, E.; Clifford, J. N.; Haque, S. A.; Durrant, J. R.; Garcia-Belmonte, G.; Bisquert, J. J. Appl. Phvs. 2004, 96, 6903-6907.

(17) Kopidakis, N.; Neale, N. R.; Frank, A. J. J.Phvs. Chem. B 2006, $110,12485-12489$.

(18) Clifford, J. N.; Palomares, E.; Nazeeruddin, M. K.; Gratzel, M.; Nelson, J.; Li, X.; Long, N. J.; Durrant, J. R. J. Am. Chem. Soc. 2004, 126, $5225-5233$.

(19) Galoppini, E.; Guo, W. Z.; Qu, P.; Meyer, G. J. J. Am. Chem. Soc. 2001, 123, 4342-4343.

(20) Galoppini, E.; Guo, W. Z.; Zhang, W.; Hoertz, P. G.; Qu, P.; Meyer, G. J. J. Am. Chem. Soc. 2002, 124, 7801-7811.

(21) Piotrowiak, P.; Galoppini, E.; Wei, Q.; Meyer, G. J.; Wiewior, R. J. Am. Chem. Soc. 2003, 125, 5278-5279.

(22) Gaal, D. A.; McGarrah, J. E.; Liu, F.; Cook, J. E.; Hupp, J. T. Photochem. Photobiol. Sci. 2004, 3, 240-245.

(23) Hamann, T. W.; Brunschwig, B. S.; Lewis, N. S. J. Phys. Chem. B 2006, 110, 25514-25520.

(24) Palomares, E.; Clifford, J. N.; Haque, S. A.; Lutz, T.; Durrant, J. R. J. Am. Chem. Soc. 2003, 125, 475-482.

(25) Kay, A.; Gratzel, M. Chem. Mater. 2002, 14, 2930-2935.

(26) Diamant, Y.; Chappel, S.; Chen, S. G.; Melamed, O.; Zaban, A. Coord. Chem. Rev. 2004, 248, 1271-1276.

(27) Chen, S. G.; Chappel, S.; Diamant, Y.; Zaban, A. Chem. Mater. 2001, 13, 4629-4634.

(28) Law, M.; Greene, L. E.; Radenovic, A.; Kuykendall, T.; Liphardt, J.; Yang, P. D. J.Phvs. Chem. B 2006, 110, 22652-22663.

(29) O'Regan, B. C.; Scully, S.; Mayer, A. C.; Palomares, E.; Durrant, J. J.Phvs. Chem. B 2005, 109, 4616-4623. 
(30) Hamann, T. W.; Martinson, A. B. F.; Elam, J. W.; Pellin, M. J.; Hupp, J. T. Prepr. Pap.-Am. Chem. Soc., Div. Fuel Chem. 2007, 52, 778779 .

(31) Guo, J. C.; She, C. X.; Lian, T. Q. J. Phvs. Chem. C 2007, 111, 8979-8987.

(32) Site-independent light harvesting, followed by rapid dye-to-dye energy transfer, however, could conceivably allow injection to be funneled through a small number of dyes adsorbed at pinhole sites. Similarly, rapid dye-to-dye hole transfer could conceivably allow electron recombination to be mediated efficiently by a small number of dyes adsorbed at pinhole sites.

(33) Ritala, M.; Leskela, M. In Handbook of Thin Film Materials; Nalwa, H. S., Ed.; Academic Press: San Diego, CA, 2001; Vol. 1, p 103

(34) Elam, J. W.; Martinson, A. B. F.; Pellin, M. J.; Hupp, J. T. Chem. Mater. 2006, 18, 3571-3578.

(35) Hamann, T. W.; Martinson, A. B. F.; Elam, J. W.; Pellin, M. J.; Hupp, J. T. Adv. Mater. 2008, 20, 1560-1564.

(36) Hamann, T. W.; Martinson, A. B. F.; Elam, J. W.; Pellin, M. J.;

Hupp, J. T. J. Phvs. Chem. C 2008, 112, 10303-10307.

(37) Martinson, A. B. F.; Elam, J. W.; Hupp, J. T.; Pellin, M. J. Nano Lett. 2007, 7, 2183-2187.

(38) Elam, J. W.; Baker, D. A.; Hryn, A. J.; Martinson, A. B. F.; Pellin, M. J.; Hupp, J. T. J. Vac. Sci. Technol., A 2008, 26, 244-252.

(39) Nefedov, V. A.; Nefedova, M. N. Zh. Obshch. Khim. (translated) 1996, 36, 122-126.

(40) Phillips, L.; Lacey, A. R.; Cooper, M. K. J. Chem. Soc., Dalton

Trans. 1988, 1383-1391.

(41) Kovar, R. J.; Rausch, M. D.; Rosenber, H. Organometallics Chem.

Synth. 1971, 1, 173-181.

(42) Connelly, N. G.; Geiger, W. E. Chem. Rev. 1996, 96, 877-910. 7398 .

43) Cameron, P. J.; Peter, L. M. J. Phvs. Chem. B 2005, 109, 7392

(44) Alarcon, H.; Hedlund, M.; Johansson, E. M. J.; Rensmo, H.; Hagfeldt, A.; Boschloo, G. J. Phys. Chem. C 2007, 111, 13267-13274.

(45) Palomares, E.; Clifford, J. N.; Haque, S. A.; Lutz, T.; Durrant, J. R. Chem. Commun. 2002, 1464-1465.

(46) Lewis, N. S. J. Phys. Chem. B 1998, 102, 4843-4855.

(47) Zhang, X. T.; Sutanto, I.; Taguchi, T.; Meng, Q. B.; Rao, T. N.; Fujishima, A.; Watanabe, H.; Nakamori, T.; Uragami, M. Sol. Energy Mater. Sol. Cells 2003, 80, 315-326.

(48) Kumara, G.; Tennakone, K.; Perera, V. P. S.; Konno, A.; Kaneko,

S.; Okuya, M. J. Phys. D: Appl. Phys. 2001, 34, 868-873.

(49) Peter, L. M. J. Phvs. Chem. C 2007, 111, 6601-6612.

(50) Moser, J. E.; Punchihewa, S.; Infelta, P. P.; Gratzel, M. Langmuir 1991, 7, 3012-3018.

(51) Attempts were made to enhance the injection yield and improve the photocurrent by adding $\mathrm{LiClO}_{4}(30 \mathrm{mM})$ to the electrolyte, as previous work implies that lithium cations lower the conduction band edge, thereby increasing the driving force for injection. Kelly, C. A.; Farzad, F.; Thompson, D. W.; Stipkala, J. M.; Meyer, G. J. Langmuir 1999, 15 (19), 7047-7054; Redmond, G.; Fitzmaurice, D. J. Phys. Chem. 1993, 97 (19), 1426-1430. No appreciable improvement was found.

(52) Haque, S. A.; Palomares, E.; Cho, B. M.; Green, A. N. M.; Hirata, N.; Klug, D. R.; Durrant, J. R. J. Am. Chem. Soc. 2005, 127, 3456-3462.

(53) Kuciauskas, D.; Monat, J. E.; Villahermosa, R.; Gray, H. B.; Lewis,

N. S.; McCusker, J. K. J. Phys. Chem. B 2002, 106, 9347-9358.

(54) Smeigh, A. L.; Katz, J. E.; Brunschwig, B. S.; Lewis, N. S.; McCusker, J. K. J. Phvs. Chem. C 2008, 112, 12065-12068.

(55) Wenger and co-workers have suggested that the slow-injecting fractions of the dye population correspond to aggregated species. (See: Wenger, B.; Gratzel, M.; Moser, J.E. J. Am. Chem. Soc. 2005, 127 (2), 12150-12151.) If aggregation could be eliminated, high-injection yields presumably could be sustained even in the presence of barrier layers. Alternatively, the development of suitable dyes featuring much longer excited-state lifetimes could offer a means for achieving high injection yields in the presence of barrier layers.

(56) Zaban, A.; Greenshtein, M.; Bisquert, J. ChemPhvsChem 2003, 4, $859-864$.

(57) Bisquert, J.; Zaban, A.; Greenshtein, M.; Mora-Sero, I. J. Am. Chem. Soc. 2004, 126, 13550-13559.

(58) Brown, K. N.; Gulyas, P. T.; Lay, P. A.; McAlpine, N. S.; Masters, A. F.; Phillips, L. J. Chem. Soc. Dalton Trans. 1993, 6, 835-840. (59) Gaal, D. A.; Hupp, J. T. J. Am. Chem. Soc. 2000, 122, 1095610963.

(60) Kelly, C. A.; Farzad, F.; Thompson, D. W.; Stipkala, J. M.; Meyer, G. J. Langmuir 1999, 15, 7047-7054.

(61) Redmond, G.; Fitzmaurice, D. J. Phvs. Chem. 1993, 97, 14261430.

(62) Abrahamsson, M.; Jager, M.; Osterman, T.; Eriksson, L.; Persson, P.; Becker, H. C.; Johansson, O.; Hammarstrom, L. J. Am. Chem. Soc. 2006, $128,12616-12617$.

(63) Wenger, B.; Gratzel, M.; Moser, J. E. J. Am. Chem. Soc. 2005, 127, 12150-12151.

(64) Karthikeyan, C. S.; Peter, K.; Wietasch, H.; Thelakkat, M. Sol. Energy Mater. Sol. Cells 2007, 91, 432-439.

(65) Martinson, A. B. F.; McGarrah, J. E.; Parpia, M. O. K.; Hupp, J. T. Phys. Chem. Chem. Phys. 2006, 8, 4655-4659.

(66) Galoppini, E.; Rochford, J.; Chen, H.; Saraf, G.; Lu, Y.; Hagfeldt, A.; Boschloo, G. J. Phvs. Chem. B 2006, 110, 16159-16161.

(67) Law, M.; Greene, L. E.; Johnson, J. C.; Saykally, R.; Yang, P. D. Nat. Mater. 2005, 4, 455-459.

(68) Splan, K. E.; Hupp, J. T. Langmuir 2004, 20, 10560-10566.

JP807395G 